\title{
Experimentos ontológicos. Variações Queer
}

Ontological experiments. Queer Variations

Experimentos ontológicos. Variaciones queer

\section{Dolores Galindo}

Universidade Federal do Mato Grosso, Cuiabá, MT, Brasil.

\begin{abstract}
Resumo
O presente texto interroga a noção de experimentos. Deslocando a atenção do debate sobre sexo e heteronormatividade para relacionalidades entre humanos e não/humanos, insere-se numa imaginação fabulativa queer voltada às ontologias variáveis do contemporâneo que não podem ser homogeneizadas por um decretado fim das dicotomias. São apresentadas notas sobre experimentos em dança e psicologia social que se configuram como apontamentos iniciais de um programa de pesquisa em andamento.
\end{abstract}

Palavras-chave: Experimentos, Ontologias, Queer, Arte Contemporânea, Psicologia Social.

\begin{abstract}
This essay interrogates the notion of experiment. Displacing the debate from sex and heteronormativity to the relationship between humans and non-humans, it proposes a fable like queer imagination turned to contemporary variable ontologies that cannot become homogeneous by an end of dichotomies enactment. Notes on dance and social psychology experiments are presented as initial propositions of an ongoing research program.
\end{abstract}

Key-words: Experiments, Ontologies, Queer, Contemporary Art, Social Psychology.

\section{Resumen}

Este ensayo interroga la noción de experimento. Desplazando la atención de lo debate sobre el sexo y la hetenormatividad para las relaciones entre humanos e no humanos, se inscribe en una imaginación fabularía queer direccionada a las ontologías variables contemporáneas que no pueden ser homogeneizadas por un decretado fin de la dicotomías. Son presentadas notas sobre experimentos con danza y psicología social que se configuran como proposiciones iniciales de un programa de investigación en corso.

Palabras llave: Experimentos, Ontologías, Arte Contemporánea, Psicología Social. 


\section{Experimentos ontológicos.}

\section{Inquietações Queer}

"Quem se importa com experimentos"? A indagação que inicia esse trabalho veio da recusa recebida por Ian Hacking (2009a) quando submeteu um artigo, no qual explorava as relações entre experimentação e teoria, a periódicos científicos de diversas origens disciplinares. A junção do termo "experimento" que nos remete ao domínio do empírico (ou ainda, à Psicologia Social Experimental que, desde a crise da década de 1970, tornouse uma bifurcação pouco percorrida pelos psicólogos sociais que embarcaram na deriva crítica) ao termo “ontologias”, cujo registro está ligado à metafísica, pode soar estranha. Valhamo-nos desta estranheza.

Em trabalho anterior (Galindo \& Méllo, 2010), empregamos o termo experimento para nos referirmos às práticas de coletivos queer-copyleft, que visavam não apenas personalizar $o$ corpo por meio de novos aditivos, mas desterritorializá-lo, não o subordinando às prescrições. Nomeamos tais práticas como piratarias de gênero, por indicarem agenciamentos que atuam na desorganização de fronteiras e no estabelecimento de outras combinações entre fluxos semióticos, informacionais e biológicos. As fronteiras são sempre virtuais: as criamos e recriamos para vivermos. Piratarias desvirtuam (tiram a virtude, adulteram) as cartas de navegação, os mapas, as prescrições. Promovem a plasticidade ampliando ou restringindo os espaços corporais: materialização da vida.

No texto presente, interrogamos a noção de experimentos, deslocando nossa atenção do debate sobre sexo e heteronormatividade para relacionalidades entre humanos e não/humanos. Inserimo-nos na imaginação fabulativa queer voltada às ontologias variáveis do contemporâneo que não podem ser homogeneizadas por um decretado fim das dicotomias. Como recurso para fabulação, recorremos às figurações que deslizam entre o literal e o fictício, sem que encontrem fixidez. Figurar é um dos principais recursos de experimentação desenvolvidos por Donna Haraway (2000; 2004; 2008), que reconhece $\mathrm{o}$ caráter difuso $\mathrm{e}$ transversal do termo, delimitando-o como uma possibilidade de abarcar o que seria, numa lógica excludente, tido como contraditório ou numa perspectiva realista simples como não existente.

Dentre as figurações do universo fantástico de Donna Haraway podemos citar os ciborgues (Haraway, 2000), o rato do câncer (Haraway, 2004) e 
animais de companhia (Haraway, 2008) entrelaçados por ela numa narrativa de parentesco. Braidotti (2006) vê na criação deste sistema de parentesco uma maneira nova de pensar conexões com tecno-outros que instaura uma dimensão ética a cada movimento ontológico: mundos relacionais sendo feitos $\mathrm{e}$ refeitos, transformando o chamado "nó górdio" que distingue humanos de não/humanos em movimentos, sem que se diga superada a linha divisória entre eles (Latour, 1994).

A arte é, sem dúvida, uma das instâncias nas quais mundos - mesmo não imediatamente atualizáveis - podem ser tomados como tropos para a experimentação pelo estranhamento e encantamento. A ficção como experimento de figuração, assim como a tecnociência, é, em si, um exercício reflexivo (Haraway, 1994; 1999). Figurar é mergulhar nos modos de viver - um mergulho atento às relacionalidades e às maneiras como "nos tornamos com" (Haraway, 2007). Nas figurações, os referentes são passagens, trânsitos que se constituem em dispositivo para criação. Sendo do âmbito da proposição, as figurações não ilustram mundos, inventam-nos e neles se imiscuem.

Pensamos como Giffney e Hird (2008) que é importante queerizar os não/humanos, indagando-os sobre as políticas ontológicas que se fazem presentes no que/quem se torna humanos, não/humanos, in/humanos. Seguindo o argumento de Butler (2008) ao discutir o conceito de abjeção, o debate queer sempre teve como um dos seus fulcros questões ontológicas nas quais a heteronormatividade é um dos eixos, mas não o único. Veja-se o que pontua Butler, em entrevista cedida a Prins e Meijer (2002, p. 159), sobre o entrelaçamento do seu trabalho sobre abjeção e proposições/ficções ontológicas:

Em parte, vejo-me trabalhar no contexto de discursos que operam através de argumentos ontológicos não há um ator por trás do ato recirculando o há para produzir um contraimaginário à metafísica dominante. Com efeito, parece-me crucial recircular e ressignificar os operadores ontológicos, mesmo que seja apenas para apresentar a própria ontologia como um campo questionado.

Mais do que apenas incluir os chamados não/humanos, o que nos faria recair numa ontologia substancialista, trata-se de queerizar a compreensão do humano enquanto gênero ou princípio normativo em torno do qual se organizam a distribuição dos entes do 
mundo, episteme que emerge quando da partição entre ciências humanas e naturais, aliás, esta separação faz parte do próprio movimento de fundação de ambas (Foucault, 1999).

Empregamos o termo experimento na esteira deleuziana da experimentação filosófica de multiplicidades como dispositivo de construção conceitual (Cardoso JR, 2010), dizendo dos modos de vida e suas resistências à estagnação (Galindo \& Méllo, 2010). Para entender o efeito da inflexão deleuziana sobre a noção de experimentos é importante remeter à conotação que este possui no cotidiano tecnocientífico, onde são vistos como separados das teorizações, sendo adjetivados técnicos.

A quais multiplicidades aludimos? A "uma multiplicidade não numérica na qual a cada estágio da divisão, pode-se falar de 'indivisíveis", (Deleuze e Guattari, 2004, p. 31). É a produção da e na diferença e não das quantidades o que está em foco (Deleuze, 1999). Os experimentos filosóficos de multiplicidades se dão na vida, movimentando sensações, devires e mundanidade extremamente materiais. Estes experimentos são filosóficos, portanto, não se dão no plano da ciência e da arte nos quais nos movemos, quando o evocamos, fazemos, portanto, uma tradução infiel.

$\mathrm{Na}$ Psicologia Social contemporânea, o experimento empregado para redução de escala da complexidade da confusa vida cotidiana e principal balizador de critérios de verdade e fiabilidade tem sido objeto de intensos debates e este uso se tornou, acertadamente, controverso (Gergen, 2007). Os experimentos se encontram ainda, inevitavelmente, ligados à discussão sobre o aparato Psi como tecnologia de governo que participa da produção de verdades que encarnam aquilo que deve ser governado, que o tornam pensável, calculável e praticável (Rose, 1988).

Depois de abordarmos o nosso primeiro termo - experimento -, passemos à discussão do termo ontologia. Classicamente, ontologia diz respeito ao estudo do ser, às condições de existência de um determinado ente; às condições de fazer-se real (Abbagnano, 1998). Todavia, este termo passou por uma grande reviravolta depois da leitura foucauldiana que o ancora na problematização do presente. $\mathrm{Na}$ acepção foucauldiana, ontologias referem-se aos modos de viver que adquirem condições de existência; diz respeito àquilo que fazemos de nós mesmos. 
O uso do termo ontologia adjetivada como histórica ou ontologia do presente trata do trabalho sobre nós mesmos como seres livres (Foucault, 1984). De acordo com Cardoso (1995), apesar desta dimensão se localizar na obra como um todo do autor, adquire maior visibilidade nos seus últimos trabalhos, onde ele "explicitamente se inscreve no que considera a tradição crítica herdeira de Kant, a de uma ontologia da atualidade" (Cardoso, 1995; p. 55).

Vale matizar que o agora/presente foucauldiano é diferente do hoje que requer ser problematizado à luz do primeiro. Conforme elucida Cardoso (1995), a problematização “desatualiza o presente, desatualiza o hoje, no movimento de uma interpelação. Nesse sentido o presente não é dado, nem enquadrado numa linearidade entre o passado e o futuro" (Cardoso, 1995; p. 52). Seguindo esta pista, podemos localizar as figurações como um recurso de desatualização do presente que interpela sobre o modo como nos constituímos, modo este cada vez mais transgendrado. As criaturas fabulosas são formas de interpelar o que chamamos de "nós mesmos" (Haraway, 2011). Quando dizemos "nós mesmos", o que/quem incluímos? $\mathrm{O}$ que/quem excluímos? A que/quem delegamos a posição de não/humanos ou mesmo de in/humanos?

Tendo a ruptura foucauldiana como ponto de inflexão para pensar sobre ontologias, Mol (2007) destaca que esta tem uma caracterização política, pois requer um processo ativo e contingente por meio do qual alguns seres (actantes, categorias etc.) adquirem existência e outros não a adquirem, devendo ser abordada sempre no plural como ontologias. $\mathrm{Na}$ mesma perspectiva, Hacking (2009b), que vê a si mesmo como um nominalista, sublinha que ontologias quando adjetivadas como históricas dizem dos modos como vivemos, valendo a pena insistir no uso deste termo.

A definição do que/quem é ou não considerado um ser com o qual nos relacionamos é variável (Latour, 1994). $\mathrm{Na}$ esteira das reflexões de Mol (2007), usamos ontologias no plural para destacar a sua vinculação com a proposição de multiplicidades. O termo é usado no plural porque aquilo que chamamos realidade é múltiplo, o mesmo se estendendo aos actantes que derivam como existentes ao ultrapassarem limiares ontológicos que os fazem inteligíveis.

Experimentar mundos fictícios e ontologias, esta é uma contribuição da arte que merece ser ressaltada ao lado 
das experimentações filosóficas, não apenas como intercessores que nos conduzam a formulação de conceitos. Donna Haraway (2004) argumenta ferozmente pela defesa desta potência da arte e da tecnociência na criação de mundos e pela responsabilidade inerente em fazê-los. Esta autora escolhe para si as zonas fictícias e potentes da fabulação, trabalhando, sobretudo, com os domínios da literatura, cinema (ambos relativos à ficção científica) e visualidades (artes plásticas) além de um amplo espectro de práticas tecnocientíficas, sobretudo, provenientes da biologia.
Um exemplo da consideração da arte como experimento ontológico pode ser encontrado nos comentários de Haraway (2007) sobre o trabalho da artista plástica Piccinini. Para ela, as esculturas e telas da artista são maneiras de experimentar ontologias que dizem de relacionalidades com os seres transgenéricos do nosso século. Nas obras de Piccinini, somos interpelados por relações de afeto: crianças e criaturas monstruosas, como em The Long Awaited, descansam uma sobre a outra (figura 1):

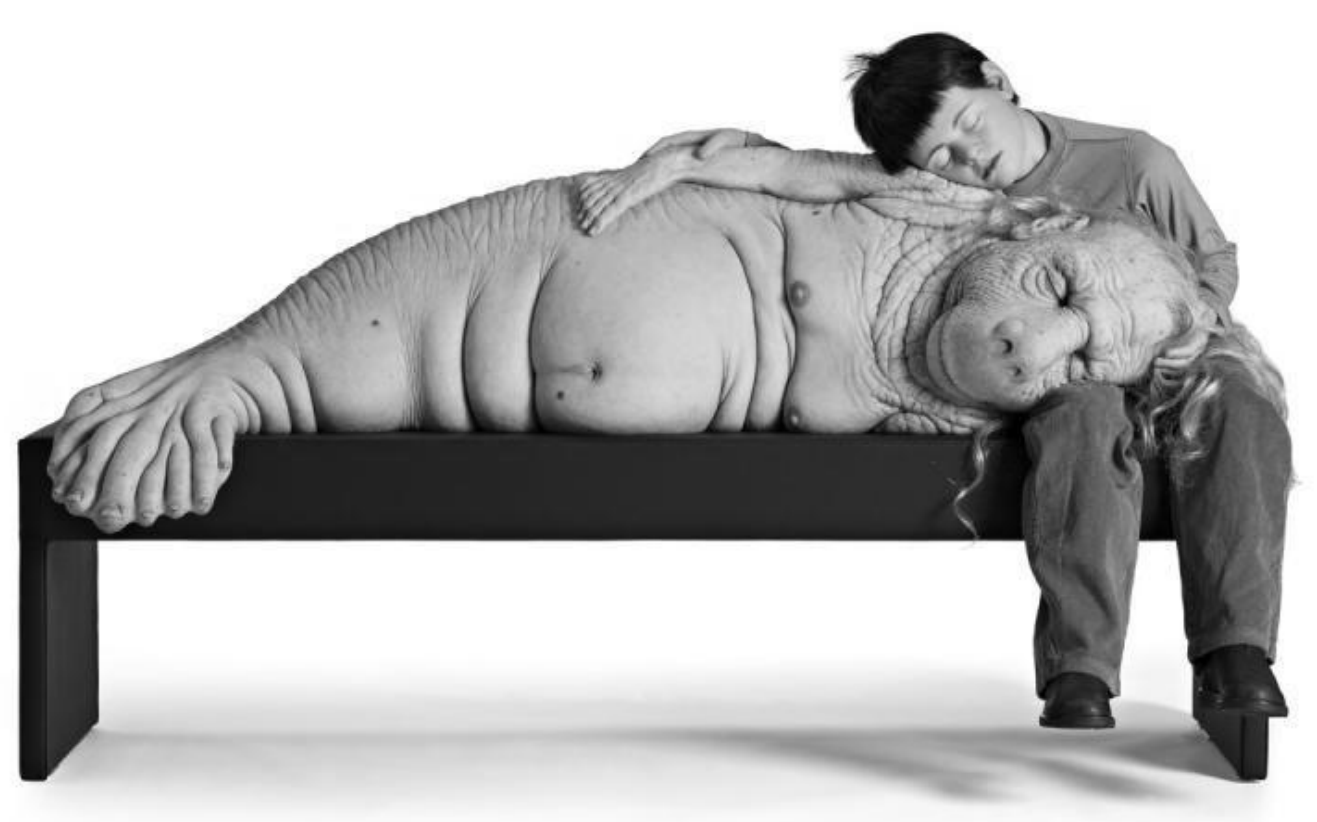

Figura 1 - Patricia Piccinni, The Long Awaited, 2008.

Fonte: http://www.patriciapiccinini.net/ 
Seguindo estas pistas, uma das vertentes de investigação que desenvolvemos no Laboratório Tecnologias, Ciências

e

\section{Contemporâneo}

(Lab.TECC)

problematiza o que chamamos de corpo próprio do pesquisador ou pesquisadora e as ontologias substancialistas fundadas na defesa de propriedades como atributos que designam e dividem a ontologia múltipla do mundo. Argumentamos pela expropriação do corpo e sua multiplicação, projeto que insere em um interesse mais amplo, concernente à experimentação de ontologias variáveis, onde as posições de sujeito e objeto; natureza e cultura; humanos e não/humanos constituem linhas nas quais nos movemos. Colocar nossa humanidade, nosso corpo à prova, é uma boa forma de romper o que podemos nomear como humanormatividade, isto é, a primazia do gênero humano como baliza para qualquer imaginação ontológica.

Não há nada de novo que fazemos. Desde a década de 1960 a arte contemporânea é pródiga de experimentos que colocam o corpo e o self unificados em questionamento, uma arte contra os corpos, contra os selves referidos a pessoalidades (Galindo, 2009). Na esteira das experimentações com o corpo da arte contemporânea, ao invés de "ter um corpo" ou "ser um corpo", experimentamos produzir corporalidades na relacionalidades com actantes que foram, ao longo do tempo, individuados em relação aos humanos: papéis e grãos.

Nem todo corpo deriva em pessoa como já o advertiram Deleuze e Guattari (1997) com as noções de devires animais. Vale matizar que para Haraway (2006), o tratamento conferido aos actantes designados animais em Deleuze e Guattari termina obnubilando as criaturas mundas em suas práticas cotidianas pela ênfase que conferem às figuras de borda onde apenas alguns animais interessam.

Nos experimentos fabulativos do Lab.TECC que apresentamos neste texto, ao invés de "ter um corpo" ou "ser um corpo", o pesquisador ou pesquisadora produz (e é produzido por) multiplicidades que não se esgotam numa pessoalidade que as precede. É um exercício fabulativo, pois na vida cotidiana, temos a sensação de unidade corporal vinculada a um self também visto como unificado (Gergen, 1992) ainda que este seja produzido por constantes arranjos (Mol, 2002) por meio dos quais adquire potência de afetação (Latour, 1999).

Ao contrário de movimentos que estão no "próprio" corpo, preferimos 
falar em múltiplas corporalidades que são produzidas, dissolvendo a unidade “corpo próprio" em multiplicidades. As multiplicidades corporais são paragens no plano da imanência que tem no plano das formas um dos seus platôs, mas não o único (Escossia \& Tedesco, 2009). Linha de fuga do pensamento interpretativo "que torna visíveis as forças enceradas nas formas, que apresenta as forças que se encontram em ação nos corpos e são as causas mais profundas de suas deformações" (Machado, 2009, p.238).

$\mathrm{Na}$ perspectiva das multiplicidades não preexiste um corpo sobre o qual construímos diferentes movimentos ontológicos. O próprio corpo adquire existência nas performances que o articulam, sendo apenas uma delas, pois, em vários momentos, os arranjos não necessariamente resultam em qualquer unidade, nem advém do humano como figura-origem ou a ele se dirigem enquanto figura-destino. Como sintetiza Cardoso JR (2010, p. 53):

(...) não é o caso de se referir a sensação à "carne", como gostaria a estética de base fenomenológica, de modo a supor que, mesmo nas composições onde não aparece a figura humana, a arte estaria tomada por um ato que doa sentido.
Quais políticas que regulam o que incluímos nas visualidades ou artes queer? Do nosso ponto de vista, inúmeros trabalhos podem ser chamados de queer se utilizamos como critério os efeitos e não o conteúdo ou temática abordada. Nesta acepção, o trabalho de Piccinini já comentado por Haraway, o trabalho de Rodrigo Braga e outros artistas, nos ajudam a pensar e experimentar ontologias não humanormativas, podendo ser interpelados como inquietações queer.

Falemos um pouco sobre $\mathrm{O}$ trabalho de Rodrigo Braga. Há algum tempo este artista recifense desenvolve uma exploração consistente de naturezasculturas iniciada com o trabalho Fantasia de Compensação (2004) no qual experimentou uma sobreposição de imagens entre humano e cachorro para compensar o que chamou de sua fraqueza diante de um animal feroz (figura 2). Apesar de ser resultante de manipulação fotográfica, o trabalho provocou intensas reações de abjeção, o corpo humano-animal evocava a morte do animal e não a incorporação do cachorro como era a proposta do artista. O híbrido não era passível de ser acolhido. 


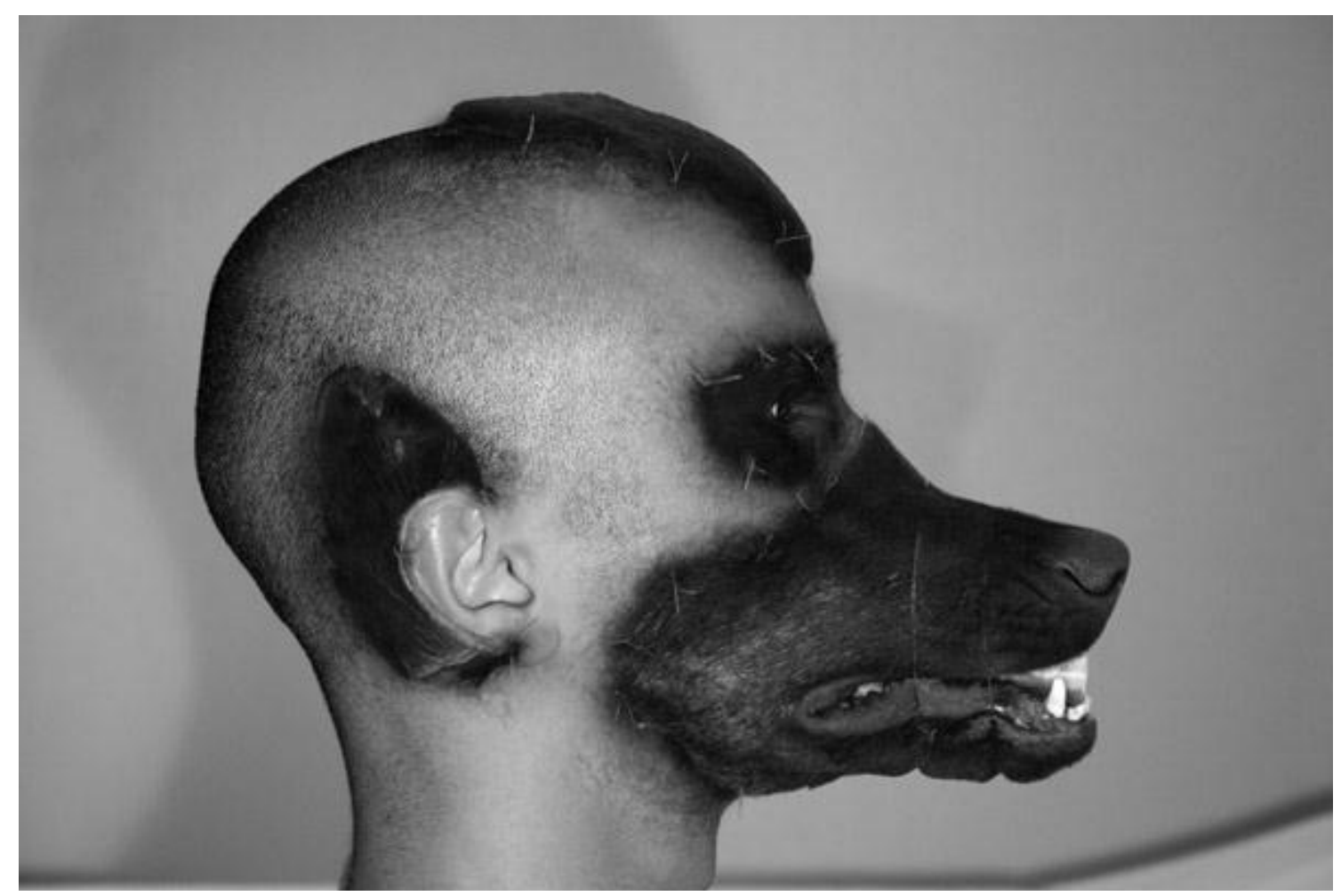

Figura 2 - Rodrigo Braga, Fantasia de Compensação, 2003.

Fonte: http://www.rodrigobraga.com.br/

Na série Comunhão (2007), caprinos. Neste trabalho, o artista Rodrigo Braga trabalhou a experimenta, também, comunhão com relacionalidade com um bode. Unindo um animal morto que se torna vívido no sua cabeça a do animal, ambos, trabalho. Separados, bode e humano, enterrados num mesmo solo, são inteligíveis - a ficção ontológica intercambiam o gesto de comunicar-se não provoca abjeção. pela fronte que é característico dos 


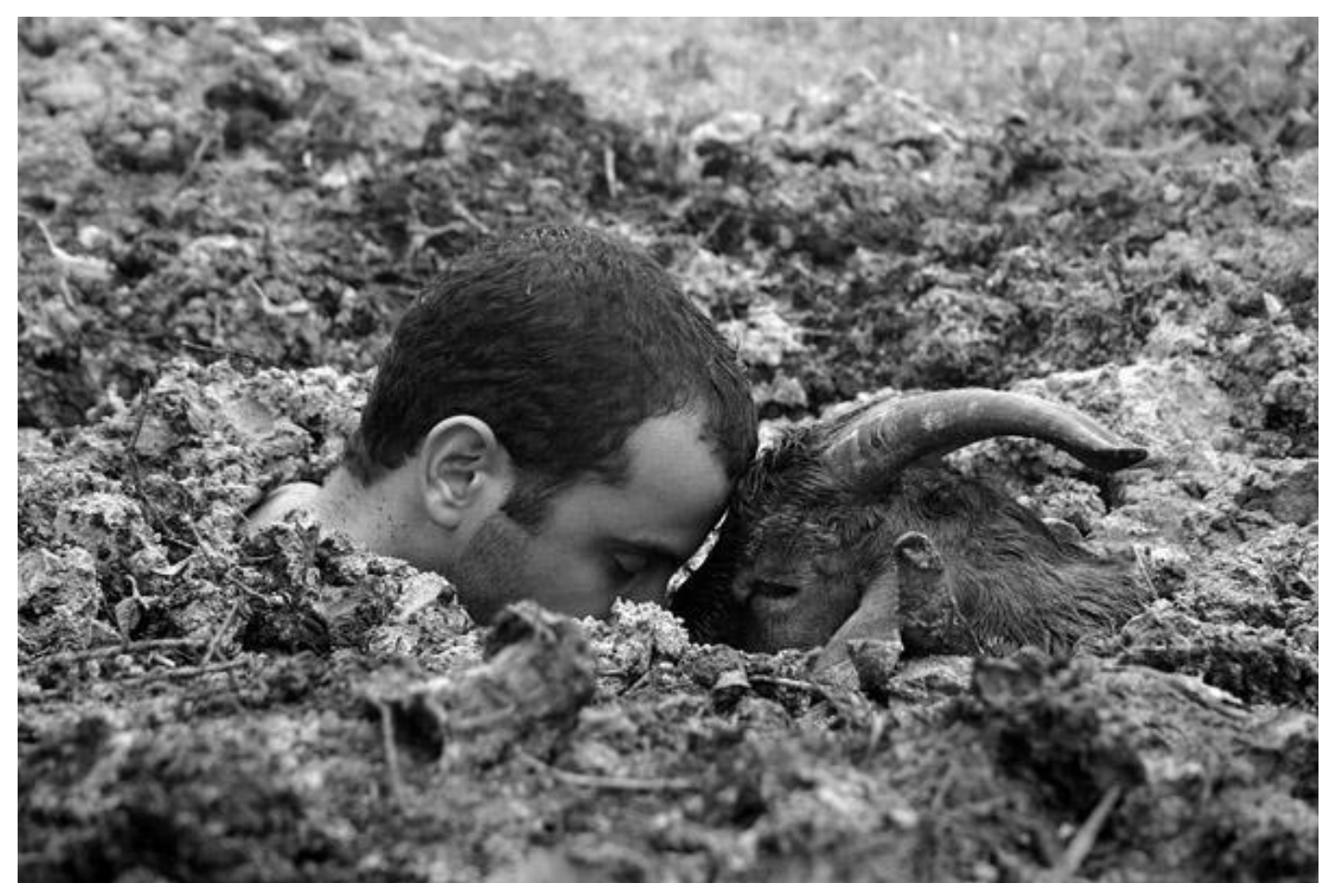

Figura 3 - Rodrigo Braga, Comunhão, 2007.

Fonte: http://www.rodrigobraga.com.br/

O pensamento de Donna (Haraway \& Azeredo, 2011). Estamos Haraway é ímpar por colocar-se na mesma deriva, aquela dos modos de radicalmente carregado de afetos e vida experimental e não de pensamento afetações nas tramas da tecnociência experimental. Com o efeito Deleuze cuja narrativa é, frequentemente, marcada pelo distanciamento. Ela nos fala do seu amor pelo rato experimental, pelos ciborgues, pelos elementos químicos. Experimenta um envolvimento que a diferencia da posição de observadora; ela está entre os seres que compõem as paisagens tecnocientíficas contemporâneas; ela é um deles. Conta-nos de histórias de amor experimentais entre homens e animais de laboratório (Haraway, 2004), discute o sofrimento das porcas brasileiras amontoadas no abate sobre o termo experimento, não há utilização de critérios de verificação característicos do laboratório - são experimentos sem verdade que tem como matéria a vida (Agamben, 2008).

Considerando o questionamento da humanormatividade, abordaremos alguns experimentos ontológicos que realizamos na interface entre Arte Contemporânea e Psicologia Social. Propusemo-nos a dançar com não humanos (Galindo \& Millioli, 2011). Ao nos propormos experimentar ontologias variáveis seria o nosso 
trabalho queer? A pergunta permanecerá em aberto.

Em De Conceitos, criado para o Circuito Cultural Setembro Freire 2010, tomando papéis com poemas como matéria para criação, a artistapesquisadora Daniela Millioli produziu arranjos que tornam visíveis multiplicidades corporais (tato, olfato etc.), e atributos concernentes às materialidades com as quais se dançam (viscosidade, aspereza etc.), emergentes do contato com papéis, seus parceiros de dança (figura 4).

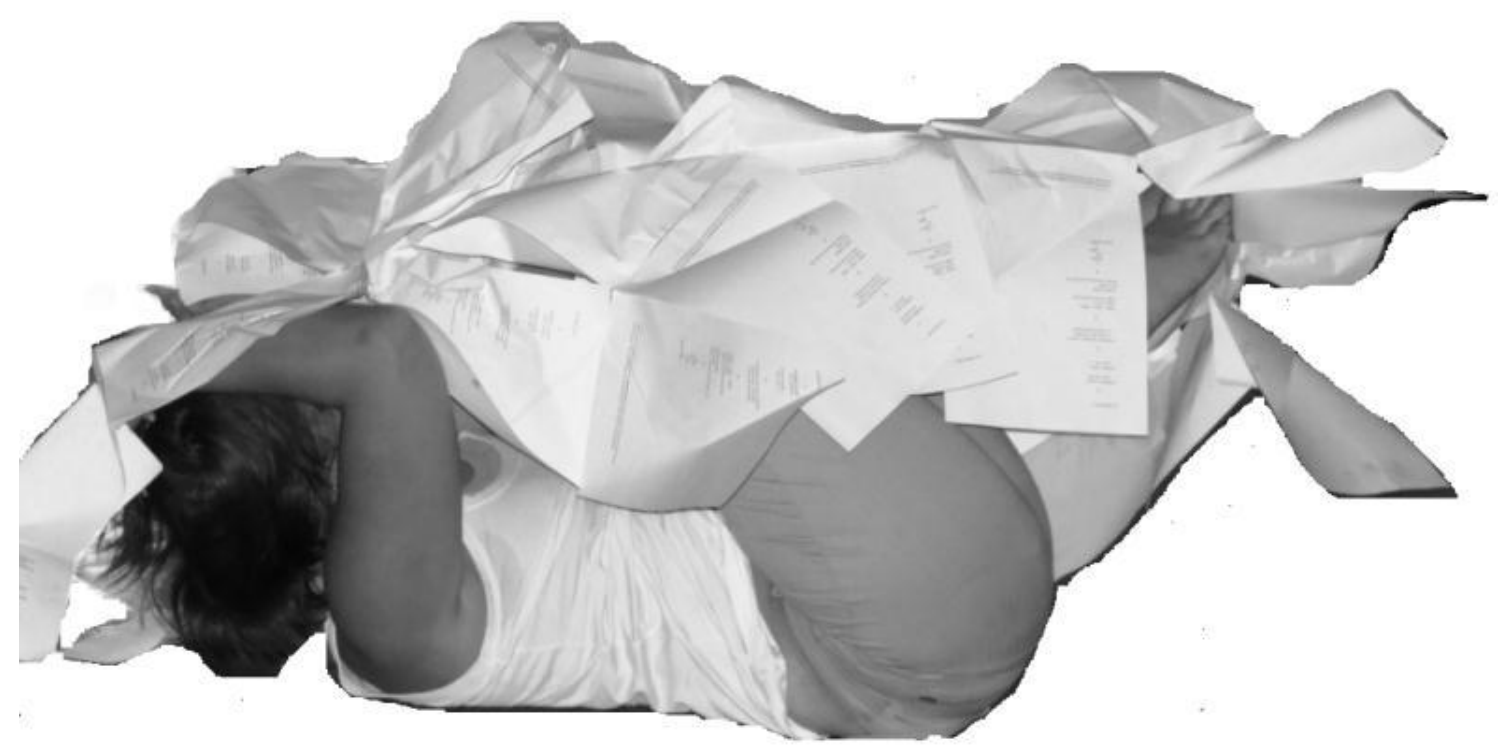

Figura 4 - Daniele Millioli, Embrulhada, De Conceitos, 2010.

O primeiro projeto foi um ensaio para que lográssemos trabalhar relacionalidades com não/humanos aos quais se atribui a propriedade de viventes. No segundo trabalho, (De) Dentro Leguminosas, criado para o projeto Leituras do Movimento do SESC Arsenal 2010, a mesma artistapesquisadora tomou grãos de soja como companheiros para criar danças. A noção espécies companheiras de Haraway (2008) contribuiu para a criação de uma figuração - leguminosas dançarinas - que, incorporando diferentes práticas, convida a habitar um mundo que vai dos cultivares transgênicos às prateleiras dos supermercados (Galindo \& Miliolli, 2012).

Transportada para a criação em dança, a soja transforma-se em figuração de uma natureza dançante, que traduz a relacionalidade na construção de mundos, onde a humanormatividade é posta em questão. Os grãos interpelaram a dançarina, ora 
com o peso de muitos quilos atados ao corpo expropriado pelo cansaço, ora pelos odores de ração animal durante sua compra, ou pela sua inclusão como parte da ambiência familiar, ao repousar em casa depois dos exercícios na sala de dança. Este experimento ontológico estava carregado de afeto, de relações de amor, ódio, agonia (Braidotti, 1996; Haraway, 2000; 2004) e de dilemas como o de chamar a soja transgênica de espécie companheira.

A escolha da soja não foi aleatória: ela é pregnante em Mato
Grosso onde se deu o processo de criação, movimentando o agronegócio, mobilizando memórias familiares, provocando o tráfego de imensas carretas que cortam as estradas durante as safras. Nos campos, a soja transgênica demarca o solo com a exibição dos tipos de sementes plantadas, uma forma de controle do produto comprado pelos agricultores. Dessa forma, dançar com a soja é fazêlo com as práticas nela incorporadas. É um experimento ontológico radicalmente localizado (Figura 5):

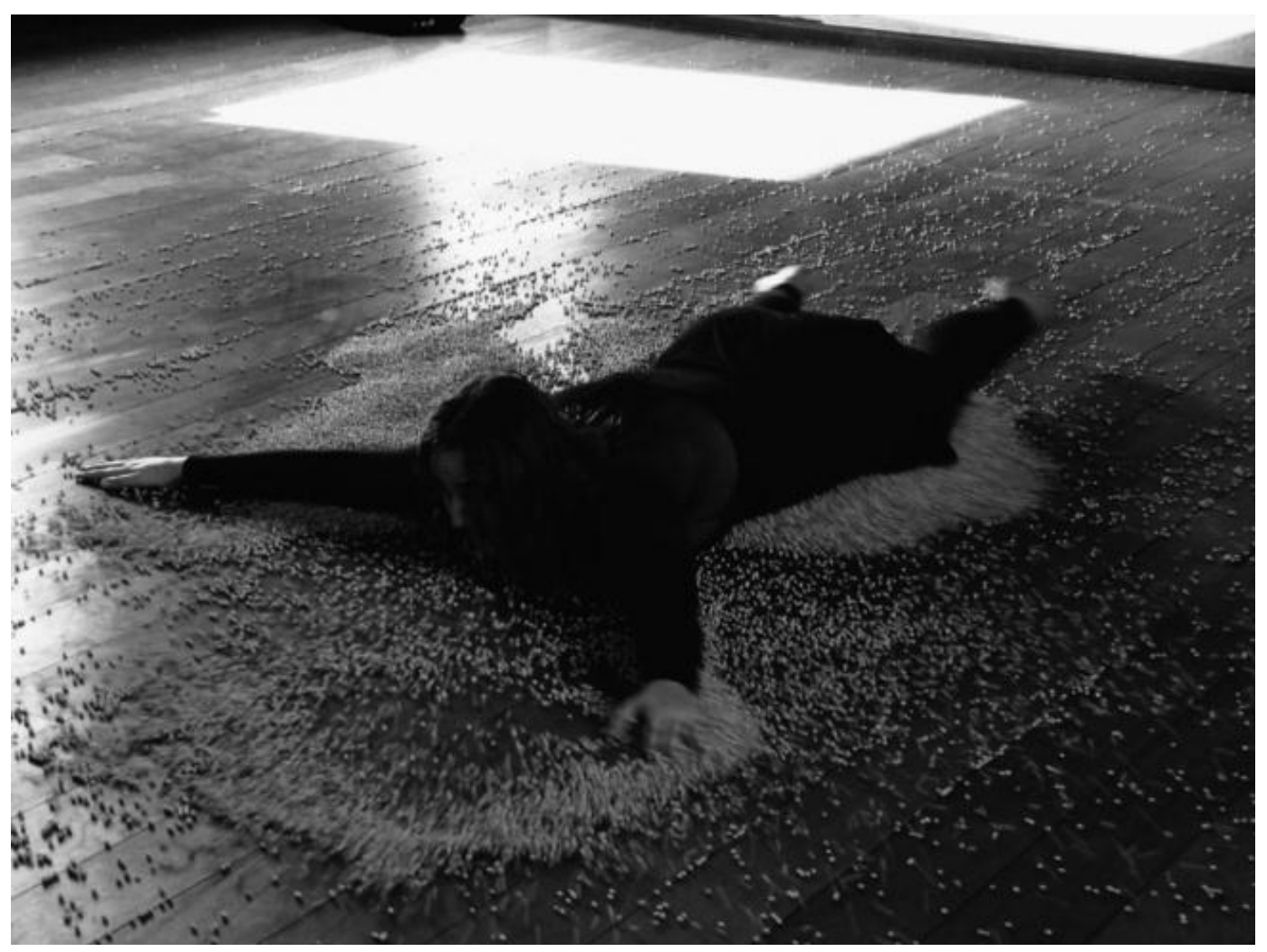

Figura 5: Daniele Millioli, (De) dentro Leguminosas, 2011.

Na dança com os grãos de soja, a artista-pesquisadora buscou experimentar ontologias variáveis, movendo-se no contínuo que, pelo hábito (Spink, 2003), costumamos ver de maneira dicotômica: natureza e 
cultura, humanos e não/humanos e assim por diante. Os grãos de soja objetam, contrapõem, respondem, resistem e, a isso, Latour (1999) chama de recalcitrância, que é uma questão de não domínio dos humanos sobre os demais actantes que o rodeiam (Arendt, 2007).

$\mathrm{Na}$ perspectiva das multiplicidades, dançar com a soja passou por dessubstancializar o corpo, abrindo-o às relacionalidades que, reais e fabulativas, aproximam-se do não vivível. Dançar com uma leguminosa? Pode uma leguminosa dançar senão numa fábula? Inevitavelmente somos conduzidas ao parentesco entre $\mathrm{o}$ próprio método experimental (aquilo que não colocamos em prática) e a arte (aquilo que fazemos), tópico que, todavia, não abordaremos nesse texto, mas que constitui matéria de nossas reflexões atuais.

\section{Em $O$ que é a filosofia?,} Deleuze e Guattari (2004) argumentam que a arte é um ser de sensação que se mantém de pé por si mesmo. Essa proposição é provocativa quando deslocada para a dança, pois os grãos de soja sozinhos repousam como ração, alimento, mas não como uma leguminosa bailarina, o mesmo se aplicando à bailarina. Talvez a dança seja demasiadamente efêmera para ser vista como um ser de sensação que se sustenta por si mesmo. A efemeridade da dançarina encontra uma bela síntese em Badiou (2002):

\begin{abstract}
A dançarina é esquecimento milagroso de todo seu saber de dançarina, ela não executa qualquer dança, é essa intensidade retida que manifesta o indecidido do gesto. Na verdade, a dançarina suprime toda dança que sabe por que dispõe de seu corpo como se ele fosse inventado. De modo que o espetáculo da dança é o corpo subtraído a todo saber de um corpo, o corpo como eclosão (p. 90).
\end{abstract}

$\mathrm{Na}$ conexão entre corpo dançante e pesquisa, vale matizar a importância de não substituir o cogito cartesiano pelo eu corporal e, ou seja, substituir o "eu penso" pelo "eu sinto", o que nos levaria a uma matriz fenomenológica. $\mathrm{Na}$ acepção deleuziana, as sensações possuem componentes materiais e virtuais de modo que se inscrevem em um plano que não se reduz a estas, pois as multiplicidades se fazem nos devires que se dão entre elas (Cardoso JR, 2010).

A dicotomia entre experimento e teorização, com infravalorização do primeiro, ainda permanece, apesar das várias críticas a ela dirigidas (Haraway, 
2000; 2004; Hacking, 2009a; 2009b), o mesmo se observa nas relações entre arte e pensamento (Badiou, 2002). Os experimentos na interface entre dança e psicologia social que conduzimos podem, facilmente, ser assimilados à ausência de método ou a uma experiência sem potência heurística. Mas, falamos de experimentos e não de método experimental e de experimentos sem verdade, imanentes, feitos na vida, feitos como modos de viver.

Deleuze (1997), em Imanência, uma vida, lembra que o elemento sensação remete a um empirismo simples, pois esta seria um corte, uma pausa no fluxo de consciência. Daí usar o termo devir que seria, justamente, aquilo que se instala entre uma sensação e outra, correspondendo ao plano das intensidades. Linha de fuga do pensamento interpretativo e "que torna visíveis as forças enceradas nas formas, que apresenta as forças que se encontram em ação nos corpos e são as causas mais profundas de suas deformações" (Machado, 2009, p.238).

Sem substituir a humanormatividade por outro ideal, igualmente normativo, correspondente ao pós-humano (Prins \& Meijer, 2002) ou ao pós-gênero (Haraway \& Gane, 2007), restam-nos experimentos ontológicos mundanos, localizados, parciais. Retornando à pergunta que dá título ao ensaio, afirmemos que experimentos importam às ontologias do presente orientadas por inquietações queer. Que forças encerram e atravessam as ontologias variáveis que se furtam às substâncias? O que nos dizem os corpos expropriados do que fazemos de nós mesmos?

\section{Referências}

Abbagnano, N. (1998) Dicionário de Filosofia. São Paulo: Martins Fontes.

Agamben, G. (2008). Barterbly, Escrita da potência, ou da contingência seguido de bartleby, o escrivão de Herman Melville. Lisboa: Assirio e Alvim.

Arendt, R. (2007). Considerações sobre os conceitos de recalcitrância $e$ de plasma e sua relação com o conceito de não domínio na obra de Bruno Latour. Em V Congresso Norte-Nordeste de Psicologia, Maceió. CD-ROM.

Badiou, A. (2002). Pequeno manual de inestética. São Paulo: Estação liberdade.

Braidotti, R. (2006). Posthuman, All Too Human: Towards a New Process Ontology. Theory, Culture \& Society, 23, 197-208. 
Butler, J. (2005) Humain, Inhumain. Le travail critique des normes. Entretiens. Paris: Éditions Amsterdam.

Butler, J. (2008). Problemas de gênero: feminismo e subversão $d a$ identidade. Rio de Janeiro: ed. Civilização.

Cardoso, I. (1995). Foucault e a noção de acontecimento. Tempo Social; Rev. Sociol. USP, 7(1-2), 53-66.

Cardoso JR, H. (2010). Arte e filosofia como disciplinas das multiplicidades: problemas filosóficos e problemas estéticos em interferência intrínseca, segundo Deleuze. Artefilosofia (UFOP), 1, 49-66.

Deleuze, G. (1997). A imanência: uma vida. Em. J. Vasconcelos \& M. Fragoso (orgs.). Gilles Deleuze, imagens de um filósofo da imanência (pp. 15-19). Londrina: UEL, 1997.

Deleuze, G. (1999). Bergsonismo. São Paulo: editora 34.

Deleuze, G. \& Guattari, F. (1997). Devir-intenso, Devir-animal, Devir-imperceptível. Em J. Vasconcellos \& M. Fragoso (orgs.). Mil Platôs - capitalismo e esquizofrenia. São Paulo: editora 34.
Deleuze, G. \& Guattari, F. (2004). O que é a filosofia? São Paulo: Editora 34.

Escossia, L. \& Tedesco, S. (2009). O coletivo de forças como plano de experiência cartográfica. Em E. Passos; V. Kastrup \& L. Escossia. (Orgs.). Pistas do método cartográfico. Porto Alegre: Sulinas.

Foucault, M. (1984). História da sexualidade II: o uso dos prazeres. Rio de Janeiro, Edições Graal.

Foucault, M. (1999). As palavras e as coisas: uma arqueologia das ciências humanas. $8^{\circ}$ ed. São Paulo: Martins Fontes.

Galindo, D. (2009). Segurança da vida, uma questão artística? Concinnitas (Rio de Janeiro), 15, $1-14$.

Galindo, D. \& Millioli, D. (2011). Dançando com a pesquisa: invenção, ciência e cotidiano. Em Anais do $2^{\circ}$ Encontro Nacional de Pesquisadores em Dança. Porto Alegre, RS, Brasil.

Galindo, D \& Millioli, D. (2012). Leguminosas dançarinas: queer(y)ng com não/humanos. Em: D. Galindo \& L. Lemos-deSouza (orgs.), Gênero $e$ Tecnologias. Tecnologias do 
Gênero: estudos, pesquisas e poéticas. Cuiabá: EdUFMT.

Galindo, D. \& Méllo, R. (2010). Piratarias de gênero experimentos estéticos queer-copyleft. Psico (PUCRS), 41, 239-245.

Gergen, K. (1992). El yo saturado: dilemas de identidad en el mundo contemporáneo. Barcelona: Paidós.

Gergen, K. (2007). Experimentación en Psicología social: una revaluación. Em: A. Estrada \& S. Diazgranados. Construccionismo social, aportes para el debate y la práctica. Bogotá: Ediciones Uniandes.

Giffney, G. \& Hird, M. (2008). Queering the non/human. Ashgate: Aldershot.

Hacking, I. (2009a) Entrevista com Ian Hacking: (por Paul Kennedy e David Cayley). Psicol. Soc., 21(3), 465-470.

Hacking, I. (2009b). Ontologia Histórica. São Leopoldo: Editora Unisinos.

Haraway, D. (1994). A Game of Cat's Cradle: Science Studies, Feminist Theory, Cultural Studies. Configurations: A Journal of Literature and Science, 2, 59-71. Haraway, D. (1999). Las promesas de los monstruos: Una politica regeneradora para otros inapropriables. Politica y Sociedad, 30, 121-63.

Haraway, D. (2000). Manifesto em favor dos ciborgues: ciência, tecnologia e feminismo socialista no final d século XX. Em T. da Silva (org.), Antropologia do ciborgue: as vertigens do póshumano (pp. 39-129). Belo Horizonte: Autêntica.

Haraway,

D.

(2004).

Testigo_Modesto@Segundo_Mile nio.HombreHembra@_Conoce_O ncoratón®: feminismo $\quad y$ tecnociencia. Barcelona: EdUOC.

Haraway, D. (2007). Speculative Fabulations for Technoculture's Generations: Taking Care. Recuperado em 15 de Novembro, 2011, de <http://www.patriciapiccinini.net/ essay.php>.

Haraway, D. (2008). When species meet. Minneapolis, London: University of Minnesota Press.

Haraway, D. (2011). A partilha do sofrimento: relações instrumentais entre animais de laboratório e sua gente. Horizontes Antropológicos, Porto Alegre, 17, 27-64.

Haraway, D. \& Gane, N. (2007). "When Have We Never Been Human, 
What is to be Done?". Theory, Culture and Society. 23.

Haraway, D. \& Azeredo, S. (2011). Companhias multiespécies nas natureza culturas: uma conversa entre Donna Haraway e Sandra Azerêdo. Em M. E. Maciel (Org.), Pensar/escrever o animal ensaios de zoopoética $e$ biopolítica.(pp. 389-417).

Florianópolis: Editora da UFSC.

Latour, B. (1994). Jamais Fomos Modernos: ensaio de antropologia simétrica. Rio de Janeiro: Editora 34.

Latour, B. (1999) How to talk about the body: the normative dimension on science studies. Disponível em http://www.brunolatour.fr/articles/article/077.html. Acesso em 30 de Abril de 2011. Machado, R. (2009). Deleuze, a Arte e a Filosofia. Rio de Janeiro: Zahar.

Mol, A. (2002). The Body Multiple: Ontology in Medical Practice. Durham: Duke University Press.

Mol, A. (2007). Política ontológica: Algumas idéias e várias perguntas. Em J. A. Nunes \& R. Roque (Orgs.). Objectos Impuros: Experiência sem Estudos sobre a ciência (pp.63-75). Porto: Edições Afrontamento.
Rose, N. (1988). Governando a alma: a formação do eu privado. Em T. T. Silva (org.). Liberdades reguladas. (pp.30-45) Petrópolis: Vozes.

Prins, B. \& Meijer, I. (2002). Como os corpos se tornam matéria: entrevista com Judith Butler. Rev. Estud. Fem., 10(1), 155-167.

Spink, M. (2003). Subvertendo as dicotomias instituídas pelo hábito. Athenea Digital, Revista de Pensamiento y investigación Social, 4, 1-15.

Dolores Galindo - Doutora em

Psicologia Social - PUCSP, com estágio doutoral na Universidade Autônoma de Barcelona (UAB); Docente do Programa de PósGraduação (Mestrado) em Estudos de Cultura Contemporânea, onde coordena a Linha de Pesquisa Epistemes Contemporâneas e do curso de graduação em Psicologia da Universidade Federal de Mato Grosso (UFMT). Líder do Grupo de Pesquisa Ciências, Tecnologias e Contemporâneo TECC/UFMT. Membro da Rede Centro-Oeste de Ensino e Pesquisa em Arte, Cultura e Tecnologias Contemporâneas - Rede CO3. VicePresidente da regional Centro-Oeste da ABRAPSO (2011-2012). 
E-mail de contato:

dolorescristinagomesgalindo@gmail.co

$\underline{\mathrm{m}}$

Endereço para correspondência:

Universidade Federal de Mato Grosso -

UFMT. Instituto de Linguagens /

ECCO. Av. Fernando Corrêa da Costa,

$\mathrm{n}^{\circ}$ 2367, sala 38/IL. Bairro Boa

Esperança. Cuiabá-MT - 78060-900. 